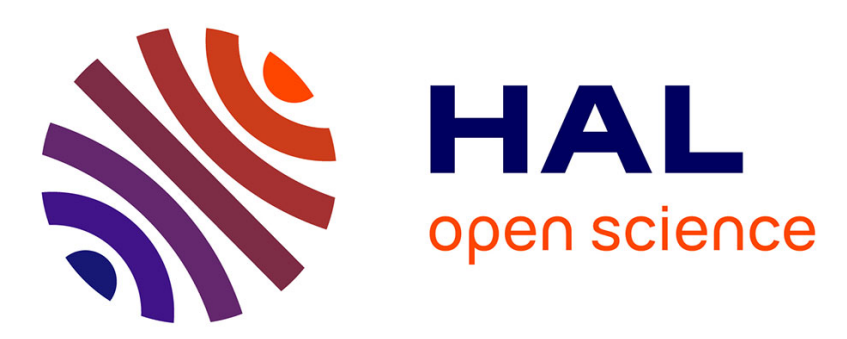

\title{
Do Human Polyoma Viruses and Human Immunodeficiency Virus Share Common Co-receptors?
}

Kalin Borissov, Iliya Tsekov, Raina Gavazova, Zlatko Kalvatchev, Radka Argirova

\section{- To cite this version:}

Kalin Borissov, Iliya Tsekov, Raina Gavazova, Zlatko Kalvatchev, Radka Argirova. Do Human Polyoma Viruses and Human Immunodeficiency Virus Share Common Co-receptors?. Journal of Medical Virology, 2009, 82 (1), pp.8. 10.1002/jmv.21674 . hal-00541153

\section{HAL Id: hal-00541153 \\ https://hal.science/hal-00541153}

Submitted on 30 Nov 2010

HAL is a multi-disciplinary open access archive for the deposit and dissemination of scientific research documents, whether they are published or not. The documents may come from teaching and research institutions in France or abroad, or from public or private research centers.
L'archive ouverte pluridisciplinaire HAL, est destinée au dépôt et à la diffusion de documents scientifiques de niveau recherche, publiés ou non, émanant des établissements d'enseignement et de recherche français ou étrangers, des laboratoires publics ou privés. 


\section{Do Human Polyoma Viruses and Human Immunodeficiency Virus Share Common Co-receptors?}

\begin{tabular}{|r|l|}
\hline Journal: & Journal of Medical Virology \\
\hline Manuscript ID: & JMV-09-1404.R3 \\
\hline Wiley - Manuscript type: & Research Article \\
\hline Date Submitted by the & 25-Aug-2009 \\
\hline Complete List of Authors: & $\begin{array}{l}\text { Borissov, Kalin; National Center of Infectious and Parasitic } \\
\text { Diseases, Virology } \\
\text { Tsekov, Iliya; National Center of Infectious and Parasitic Diseases, } \\
\text { Virology } \\
\text { Gavazova, Raina; Institute of Experimental Pathology and } \\
\text { Parasitology, Bulgarian Academy of Sciencies, Biochemistry } \\
\text { Kalvatchev, Zlatko; National Center of Infectious and Parasitic } \\
\text { Diseases, Virology } \\
\text { Argirova, Radka; National Center of Infectious and Parasitic } \\
\text { Diseases, Virology }\end{array}$ \\
\hline Keywords: & $\begin{array}{l}\text { human polyoma viruses (HPoV - JCV, BKV), HIV co-receptors } \\
\text { (CCR5, CCR2, CXCR4), Bulgarians living with HIV }\end{array}$ \\
\hline \hline
\end{tabular}

\section{S) ScholaroNE \\ Manuscript Central}


TABLE I. Genetic Polymorphisms of CCR5, CXCR4(SDF1) and CCR 2 in HIV infected Bulgarians co-infected or not infected with HPoV

\begin{tabular}{|c|c|c|c|c|c|c|c|c|c|c|}
\hline \multirow{3}{*}{$\begin{array}{l}\text { HIV } \\
\text { infected } \\
\text { patients }\end{array}$} & & \multicolumn{9}{|c|}{ Genetic polymorphism patterns of chemokine co-receptors in HIV infected Bulgarians $(n=49)$} \\
\hline & & \multicolumn{3}{|c|}{ CCR5 } & \multicolumn{3}{|c|}{ CXCR4 (SDF1) } & \multicolumn{3}{|c|}{ CCR2 } \\
\hline & & $\begin{array}{c}\text { Wild type } \\
\text { CCR5/CCR5 } \\
\text { n, }(\%)\end{array}$ & $\begin{array}{c}\text { Heterozygous } \\
\text { CCR5/CCR del } \\
32 \\
\mathrm{n},(\%)\end{array}$ & $\begin{array}{c}\text { Homozygous } \\
\text { CCR del } \\
\text { 32/CCR } \\
\text { del } 32 \\
\text { n, }(\%)\end{array}$ & $\begin{array}{c}\text { Wild type } \\
\text { SDF1- } \\
\text { G/G } \\
\text { n, }(\%)\end{array}$ & $\begin{array}{c}\text { Heterozygous } \\
\text { SDF1-G/A } \\
\text { n, }(\%)\end{array}$ & $\begin{array}{c}\text { Homozygous } \\
\text { SDF1-A/A } \\
\text { n, }(\%)\end{array}$ & $\begin{array}{l}\text { Wild } \\
\text { type } \\
\text { V/V } \\
\mathrm{n},(\%)\end{array}$ & $\begin{array}{c}\text { Heterozygous } \\
\text { V/I } \\
\mathrm{n},(\%)\end{array}$ & $\begin{array}{c}\text { Homozygous } \\
\mathrm{I} / \mathrm{I} \\
\mathrm{n},(\%)\end{array}$ \\
\hline \multirow{2}{*}{$\begin{array}{l}\text { Co-infected } \\
\text { with HPoV } \\
(\mathrm{n}=27)\end{array}$} & BKV & 11 (91.7) & \begin{tabular}{|l|l}
$1(8.3)$ \\
\end{tabular} & $0(0)$ & $7(58.3)$ & $3(25.0)$ & $2(16.7)$ & $9(75.0)$ & $3(25.0)$ & $0(0)$ \\
\hline & JCV & $11(91.7)$ & \begin{tabular}{|l}
$1(8.3)$ \\
\end{tabular} & $0(0)$ & $9(75.0)$ & $2(16.7)$ & $1(8.3)$ & $9(75.0)$ & $3(25.0)$ & $0(0)$ \\
\hline $\begin{array}{l}\text { Not } \\
\text { infected } \\
\text { with HPoV } \\
(\mathrm{n}=22)\end{array}$ & & $22(100)$ & $0(0)$ & $0(0)$ & $10(45.4)$ & $11(50.0)$ & $1(4.6)$ & $13(59.0)$ & $9(40.9)$ & $0(0)$ \\
\hline
\end{tabular}


TABLE II. Distribution of genetic polymorphim/s in patients with HIV co-infected or not infected with HPoV

\begin{tabular}{|c|l|c|c|}
\hline Patients groups & Genetic polymorphisms found & Number (\%) & $\begin{array}{l}\text { Average CD4+T cells count } \\
\text { around the moment of HPoV } \\
\text { detection }\end{array}$ \\
\hline $\begin{array}{c}\text { Persons with HIV } \\
\text { co-infected with } \\
\text { HPoV (n=27) }\end{array}$ & $\begin{array}{l}\text { Wild genotype (wt) by all three co- } \\
\text { receptors }\end{array}$ & \begin{tabular}{c}
738 \\
\cline { 2 - 4 }
\end{tabular} & $\begin{array}{c}737.0) \\
(180-1014)^{* *}\end{array}$ \\
\hline $\begin{array}{c}\text { Persons with HIV } \\
\text { not infected with } \\
\text { HPoV (n=22) }\end{array}$ & $\begin{array}{l}\text { Wild genotype (wt) by all three co- } \\
\text { receptors }\end{array}$ & $5(22.7)^{*}$ & $\begin{array}{c}602 \\
(218-1473)^{* *}\end{array}$ \\
\cline { 2 - 4 } & Polymorphism/s in one or two genes & $17(77.3)^{*}$ & $\begin{array}{c}573 \\
(253-955)^{* * * *}\end{array}$ \\
\hline
\end{tabular}

$* \mathrm{P}=0.03 ; * * \mathrm{P}=0.47 ; * * * \mathrm{P}=0.89$ 

receptors?

3 Kalin Borissov $^{1}$, Iliya Tsekov ${ }^{2}$, Rayna Gavazova $^{3}$, Zlatko Kalvatchev $^{2}$, Radka Argirova $^{1}$ 4

$5{ }^{1}$ Department of Virology, Laboratory of Retroviruses, National Center of Infectious and Parasitic

6 Diseases, Sofia, Bulgaria;

$7 \quad 2$ Department of Virology, Laboratory of Molecular Virology, National Center of Infectious and 8 Parasitic Diseases, Sofia, Bulgaria;

93 Institute of Experimental Pathology and Parasitology, Section of Biochemistry, Bulgarian 10 Academy of Sciences, Sofia, Bulgaria;

12 Correspondence to: Radka Argirova, Laboratory of Retroviruses, Department of Virology,

13 National Center of Infectious an Parasitic Diseases, 44A Boul. Stoletov, 1233, Sofia, Bulgaria

14 E-mail: radkaargirova@abv.bg, fax: +3592 8329118

16 Running head: Human Polyoma Viruses and HIV Share Common Co-receptors? 


\section{ABSTRACT}

2 Host and/or viral factors involved in human polyomavirus (HPoV) infection in persons living

3 with HIV remain unknown. A hypothesis is outlined suggesting the importance of the co4 receptors CCR5, CCR2 and CXCR4 not only for HIV, but also for HPoV. Functionally capable 5 receptors coded by wild type (wt) genotypes could facilitate internalization of HPoV in the cell

6 resulting in brain and/or kidney infection/s in HIV infected individuals.

7 Forty nine Bulgarians with HIV, all treated by HAART, without neurological and/or kidney

8 disorders, were tested for JCV and BKV and genotyped for CCR5(CCR5del32), CCR2(CCR2-

9 64I) and CXCR4(SDF1-3'A). In 27/49 (55.1\%) individuals a co-infection with HPoV was

10 identified - BKV in 12/49 (24.5\%), JCV - in another 12/49 (24.5\%) and both viruses - in 3/49

11 (6.1\%). A high frequency of wt CCR5 was found in patients with HPoV (91.7\% for BKV and $12 \mathrm{JCV}$ and in $100 \%$ with both viruses). V/V of CCR2 was presented in $75 \%$ for BKV and JCV and 13 in $66.7 \%$ for BKV plus JCV. SDF1-3'G/G predominated in JCV infected patients (75\%), while $14 \mathrm{G} / \mathrm{A}$ and $\mathrm{A} / \mathrm{A}$ genotypes were more frequent in patients with BKV (41.7\%).

15 Also, 21/22 (95.4\%) persons without HPoV infection were heterozygous for SDF1 and CCR2.

16 The number of individuals bearing wt of all co-receptors in the group of persons not infected with

$17 \mathrm{HPoV}$ was lower $(\mathrm{p}=0.03)$ than that with polymorphism/s in one or two genes (SDF1 and CCR2)

18 in the same group.

19 The results suggest a probable role of co-receptors used by HIV to facilitate infection with HPoV.

21 Key Words: human polyoma viruses (HPoV - JCV, BKV), HIV co-receptors (CCR5, CCR2, 22 CXCR4), Bulgarians living with HIV 


\section{INTRODUCTION}

2

When Highly Active Antiretroviral Therapy (HAART) for infection with HIV was

4 introduced in 1996, a number of viral and bacterial opportunistic infections associated earlier

5 with severe immunodeficiency, such as those caused by cytomegalovirus or the mycobacterium

6 avium complex, were reduced drastically [Hoffmann, 2005]. Nevertheless, some problems

7 associated with the diagnosis and treatment of other opportunistic infections remained, among

8 them the progressive multifocal leukoencephalopathy [Hoffmann, 2005].

9 In contrast to infection with cytomegalovirus or with the mycobacterium avium complex

10 progressive multifocal leukoencephalopathy does not always indicate the final stages of HIV

11 infection. Although CD4+T cells number is usually below 100/ $\mu$ l when clinical disease develops,

12 the progressive multifocal leukoencephalopathy may also occur when the CD4+ T-cell count is

13 above 200/ $\mu$ l. Since HAART was introduced, the decrease in the incidence of the progressive

14 multifocal leukoencephalopathy was not as frequent as other opportunistic infections. However,

15 progressive multifocal leukoencephalopathy is now probably the second most common

16 neurological opportunistic infection, after cerebral toxoplasmosis, in persons infected with HIV

17 [Antinori et al., 2001].

18 The human polyomaviruses (HPoV), known as JCV, BKV, WUV, KIV and MCC, are

19 small, naked, DNA containing viruses. Infection with HPoV is almost ubiquitous, asymptomatic

20 and lifelong. However, reactivation during immunosuppression, associated with mutations in the

21 transcriptional control region, that upregulates viral replication, can cause life-threatening disease

22 [Cole and Conzen, 2001]. Thus, it has been considered that JCV, the causative agent of

23 progressive multifocal leukoencephalopathy, is activated and the disease becomes symptomatic

24 only when cellular immunity is impaired. JCV reaches the central nervous system via leukocytes, 
1 where it destroys cells containing myelin sheath [Hoffmann, 2005]. On the other side, HIV-1 can

2 also infect oligodendrocytes, the cells producing myelin, resulting in production of infectious

3 virus [Albright et al., 1996].

4 BKV causes productive infection in the urinary tract. Approximately $80 \%$ of adults

5 worldwide are seropositive for BKV, though there is no evidence that BKV causes any disease in

6 the immune competent host. There is strong evidence for the association of BKV with

7 hemorrhagic cystitis, nephritis and especially with graft failure in renal transplant patients. BKV

8 remains latent in lymphocytes, the urogenital tract and brain but may be reactivated if the host

9 becomes immunocompromised [Vallbracht et al., 1993]. Little is known about the role of the

10 other HPoV (WU, KI and MC) identified recently in immunocompromised individuals [Sharp et

11 al., 2009].

12 A number of host genetic factors, including genotypes of the chemokine co-receptors

13 (CCR5, CCR2) and the SDF1, the only natural ligand of the CXCR4 co-receptor, have been

14 identified. They have an impact on susceptibility to HIV-1 infection, as well as, on progression to

15 AIDS and death [Singh et al., 2003; Su et al., 2000].

16 The brain and kidney are among the organs favoring the persistence of HPoV. This means

17 that viruses harbored there are able to evade immunological surveillance [Nathanson and

18 Gonzales-Scarano, 2007]. It appears this happens through restricted access of lymphocytes to the

19 brain across the blood-brain barrier or to infected glomerular epithelial cells across the

20 subendothelial basement membrane.

21 The onset and course of a HPoV related disease in persons infected with HIV is in most

22 cases considered to be associated with a severe impairment of the immune system and especially

23 of cell-mediated immunity. Although HAART was introduced more than a decade ago, some

24 infections, especially the progressive multifocal leucoencephalopathy remain a problem. So, 
1 factors of human and/or of viral origin should be presented and analyzed to explain the observed 2 discordance. Today, a limited number of studies are dedicated to interactions between HPoV and 3 HIV and still less - to the impact of host genetic factors for acquiring and development of these 4 opportunistic infections in persons infected with HIV [Doerries, 2004; Guerini et al. 2008].

5 The aim of this study was to demonstrate the presence of HPoV (JCV and/or BKV) in

6 Bulgarians infected with HIV but without neurological and/or kidney disorders and to analyze the 7 possible role of genetic polymorphisms of three chemokine co-receptors: CCR5 (CCR5del32), 8 CXCR4 (SDF1-3'A) and CCR2 (CCR2-64I), in relation to the presence/absence of two HPoV: $9 \mathrm{JCV}$ and BKV. Several reports discuss the receptors that can be used by HPoV. Infections with $10 \mathrm{JCV}, \mathrm{BKV}$ as well as SV40 could be blocked by pretreatment of cells with neuraminidase, 11 suggesting the receptors are sialoglycoproteins [Greenlee and O'Neill, 2002]. A recent research 12 determined that the serotonergic receptor 5HT2AR could be utilized by JCV in glial cells 13 [Elphick et al., 2004]. Nevertheless, investigation of the effect of risperidone (a potent 5HT(2A)R 14 blocker) on JCV infected cells, failed to determine a significant difference between treated and 15 naive cells, questioning the effectiveness of this substance for patients with progressive 16 multifocal leucoencephalopathy [Chapagain et al., 2008]. Therefore, JCV might employ 17 additional entry mechanisms. Similarly to other naked viruses, internalization of HPoV in the cell 18 differs substantially from the entry of enveloped viruses like HIV. There is no need for 19 membrane fusion for JCV and BKV to penetrate the cell. It has been shown that HPoV use 20 caveolar endocytosis, a receptor-dependent process [Cole and Conzen, 2001]. On the other hand,

21 before infecting macrophages and microglia in the brain, polyomaviruses could be transferred 22 by leukocytes. Viruses might exploit the co-receptors (CCR5, CXCR4 and/or CCR2), as well as $23 \mathrm{CD} 4+$ receptors and MHC class I molecules of CD8 cells, respectively. 
1 Recently, HIV-1 binding sites were discovered in brain, i.e. chemokine co-receptors could

2 facilitate the infection of macrophages and microglia not only with HIV [Cartier et al, 2005; Kaul

3 et al., 2001], but according to the proposed hypothesis, also with HPoV. If this really occurs, it

4 should be demonstrated that the CCR5, CXCR4 and/or CCR2 co-receptors presented on CD4+ T

5 cells and on other cells involved in HIV-1 brain/kidney persistent infection, are functionally

6 capable, i.e. are coded by wild type (wt) genotype resulting in active receptor proteins, not in

7 truncated ones. On the contrary, internalization of HPoV in the cell should not be supported by

8 polymorphism/s in co-receptor gene/s, probably conferring absence of HPoV infection even in

9 patients with HIV induced immunodeficiency.

10

11

12

13

14

15

16

17

18

19

20

21

22

23

24 


\section{MATERIALS AND METHODS}

2

\section{Patients and Study Design}

Forty nine blood samples collected on Gutrie cards from Bulgarians living with HIV (36

5 males and 13 females), with an average duration of HIV-1 infection 12.54 years (22 - 4), all of

6 them on treatment by HAART, with no clinical evidence for neurological and/or kidney

7 disorders, were enrolled in this study. Approval for the study was obtained from the Independent

8 Ethics Committee of National Center of Infectious and Parasitic Diseases, Sofia, Bulgaria. DNA

9 was isolated from the Gutrie cards by phenol:chlorophorm:isoamylalcochol $(25: 24: 1)$ method.

10 For every person the CD4+T cell count around the moment of detection of BKV and/or JCV was

11 registered (TABLE II).

\section{Identification of HPoV Sequences in Peripheral Blood Leucocytes}

14 For detection of JCV and BKV, qualitative real-time PCR assays were employed. BKV

15 viral genomic sequences were documented using a novel Light Upon Extension (LUX) primer 16 system as demonstrated before [Slavov et al., 2008]. For detection of JCV the primer pair JCT1

17 and JCT2 [MacKenzie et al., 2003] was used, modified for a protocol with SYBR-Green I. As

18 this is a non-specific detection system (intercalating dye) and in order to verify the specificity of

19 the amplified fragments, a dissociation analysis was performed. Only samples showing both an

20 increase in the fluorescent signal and a characteristic dissociation pattern with a specific melting

21 temperature of $75.7^{0} \mathrm{C}$, were considered positive. Measures were taken according to the molecular

22 biology guidelines in order to prevent contamination, including the use of DNA free negative 23 controls in each run. 


\section{Chemokine Co-receptor Genotyping}

Study of polymorphism and genotyping of CCR5 (CCR5del32), CXCR4 - SDF1 (SDF1-

3 3'G/A) and CCR2 (V64I) were conducted as already described [Borissov et al., 2007]. Briefly,

4 PCR and Restriction Fragment Length Polymorphism assays were carried out. Following the

5 amplification reaction, the products were subjected to restriction enzyme digestion with Msp1 for

$6 \mathrm{SDF} 1$ and BsaBI for CCR2 for $4 \mathrm{~h}$. The digestion products and the PCR product for CCR5 were

7 analyzed by agarose gel electrophoresis (for CCR5) or PAGE (for CCR2 and SDF1). Statistical

8 Chi-square (c2) analysis was used to compare the genotype frequency distribution within the

9 groups of persons infected with HIV and/or HPoV. Fisher's exact test was performed to compare

10 the average number of absolute $\mathrm{CD} 4+\mathrm{T}$ cell counts, as appropriate. A cut-off of $\mathrm{p} \leq 0.05$ was

11 considered significant. 


\section{RESULTS}

\section{Genetic Polymorphisms in HIV Infected Patients with HPoV Infection(s)}

Genotyping of DNA of 49 individuals was performed for CCR5 (CCR5del32), SDF1 3'G (SDF1-3'G/A) and CCR2 (CCR2-V64I) in order to evaluate their involvement in HIV and/or HPoV infection. Specific BKV and/or JCV sequences were identified in peripheral blood leucocytes of 27/49 (55.1\%) Bulgarians infected with HIV. No neurological symptoms and/or kidney dysfunction were observed in the patients at the time point of genetic studies. BKV as well as JCV were found in 12/49 (24.5\%) of the studied DNA samples. BKV plus JCV were detected in 3/49 (6.12\%). A high frequency of wt form of CCR5 (TABLE I) was found in patients with HIV co-infected with HPoV (11 out of 12 BKV and JCV positive samples - 91.7\% and 3 out of $3-100 \%$ for the double infected, respectively). The results obtained for wild V/V genotype of CCR2 were 9 out 12 (75\%) for each BKV and JCV and 2 out of $3(66.7 \%)$ for the BKV plus JCV positive samples (TABLE I). In the samples tested none was found with homozygous (CCR2-64I/CCR2-64I) genotype. It is of special interest that $3 / 12(25 \%)$ from the BKV and JCV infected persons showed heterozygous, CCR2/CCR2-64I, genotype. The wild genotype of SDF1-3'G/G (TABLE I) predominated in patients with JCV (75\%), while G/A and A/A genotypes were found more frequently in patients with BKV (41.7\%).

\section{Genetic Polymorphisms in HIV Infected Patients without HPoV Infection(s)}

Genetic polymorphisms profile of all three studied co-receptors in 22 out of $49(44.9 \%)$ patients living with HIV, but not infected with HPoV is represented in TABLE I, too. The results clearly demonstrate that 21 out of all $22(95.4 \%)$ HIV infected individuals without HPoV show heterozygous patterns of two co-receptors - CXCR4 (SDF1-3'A/SDF1-3' G/A) and CCR2 (CCR2/CCR2-64I). Only one person (1 out $22-4.6 \%$ ) has a homozygous pattern for the ligand 
1 of CXCR4: SDF1-3' A/A. It is worth noting that double genetic polymorphisms - those of SDF1

2 (CXCR4) and CCR2 - predominate. The explanation and importance of this finding is still

3 unclear and needs further investigation.

4 The distribution of genetic polymorphim/s in persons infected with HIV, co-infected or

5 not with $\mathrm{HPoV}$ is demonstrated in TABLE II. A significant difference $(\mathrm{p}=0.03)$ was found

6 between the wt carrying persons (for all three co-receptors) and those with polymorphism/s in

7 one or two genes coding for chemokine co-receptors within the group of individuals infected with

8 HIV but not infected with HPoV. No statistical difference was found when comparing the

9 CD4+T positive counts in all patients groups (all patients were treated by HAART of different

10 duration and protocols).

11

12

13

14

15

16

17

18

19

20

21

22

23

24 


\section{DISCUSSION}

Data are presented on the possible role of the most important co-receptors for HIV -

4 CCR5, CXCR4 (SDF1) and CCR2, for polyomaviruses' cell entry in persons infected with HIV, 5 without clinical disease or symptoms characteristic for JCV and/or BKV. Recently, synergism 6 between HIV and JCV has been demonstrated in vitro [Hoffmann, 2005]. For example, the HIV7 1-encoded Tat protein, essential for the establishment of a productive HIV-1 infection, has been 8 found to be a potent activator of the JCVL promoter. BKV T antigen is able to transactivate the 9 HIV-1 Long Terminal Repeat. Although HIV-1 expression in oligodendrocytes is regularly low, 10 the Tat protein appears to be secreted by HIV-1-infected cells. When localized in JCV-infected 11 oligodendrocytes, it could induce transcription on Tat-responsive genes [Doerries, 2004].

12 Popik et al.(2002) demonstrated the involvement of T-cell lipid rafts in the process of 13 HIV attachment [Popik et al., 2002]. According to these studies, independently of the presence of 14 CD4 [Millan et al., 1999] and CCR5 [Manes et al., 1999] in detergent-resistant membrane 15 microdomains, the distribution of CD4, CCR5, and CXCR4 receptors in T-cell lipid rafts 16 remains largely unknown. A study using immunogold electron microscopy, has shown clearly the 17 existence of homogenous microclusters of CD4 and chemokine co-receptors separated by 18 distances of less than $100 \mathrm{~nm}$, thus suggesting that these HIV-1 receptors may colocalize in rafts 19 [Singer et al. 2001]. Also, it has been shown that the assembly and budding of different viruses, 20 including HIV-1 [Nguyen and Hildreth, 2000; Ono and Freed, 2001], take place in lipid rafts.

21 Moreover, the same authors found that HIV-1 particles produced by infected $\mathrm{T}$ cells incorporate 22 raft-resident proteins and glycolipids into the viral envelope Further, it has been demonstrated 23 that raft-colocalized receptors may be crucial for entry of different pathogens, including SV40 24 [Parton and Lindsay, 1999; Pelkmans et al., 2001] and the murine leukemia virus [Lu, Silver, 
1 2000]. Bearing all these facts in mind, a hypothesis was outlined suggesting the participation of

2 co-receptors used by HIV infected cells for internalization of HPoV in the cells of the brain and

3 kidney of persons with HIV infection. In order to verify this hypothesis two groups of individuals

4 infected with HIV were compared - co-infected and not infected with HPoV. No

5 immunodeficiency at the time of HPoV detection was found (TABLE II).

6 Data presented on TABLE I demonstrate that more than $50 \%$ of HPoV and HIV infected

7 persons bear normozygous (wt) co-receptors. Heterozygocity in all co-receptors genes should be

8 considered as restricted expression but not as a lack of receptor proteins. These data support the

9 hypothesis by demonstrating the presence of functionally capable co-receptor proteins in

10 individuals infected with HIV and positive for HPoV. But this hypothesis should sound more

11 strongly if the restricted expression or even lack of more than one co-receptor protein was found

12 in persons not infected with HPoV. This conferred the special interest to see the distribution of

13 genetic polymorphism/s of the studied co-receptors in the group of persons infected with HIV but

14 not infected with HPoV (TABLE I and TABLE II).

15 The number of persons bearing wild type of all three studied co-receptors in the group of

16 persons not infected with HPoV but with HIV infection, is statistically lower $(p=0.03)$ than that

17 of persons with polymorphism/s in one or two genes (G/A and/or A/A in SDF1 and V/I in CCR2)

18 in the same group (TABLE II). No similar difference was observed in the group of HPoV-

19 infected persons (TABLE II). Additionally, only 4 out of 27 (14.9\%) of all HPoV (JCV and

$20 \mathrm{BKV}$ ) positive individuals were found to have a homozygous profile (SDF1-A/A) meaning no

21 expression of the SDF1 gene (TABLE I). This result suggests the probable role of both co-

22 receptors with a restricted or even lacking expression could facilitate the internalization of HPoV

23 in the cell. Guerini FR et al. (2008) described an association of G/A and A/A polymorphisms of

24 SDF1 in patients with HIV-related progressive multifocal leucoencephalopathy (JCV positive), 
1 but not in HIV infected persons without JCV. The results concerning SDF1 polymorphisms

2 documented in the present study differ from those observed by Guerini FR et al. (2008): all

3 patients with JCV had both no lesions characteristic for progressive multifocal

4 leucoencephalopathy, and no immunosuppression (all of them received HAART) and possibly no

$5 \mathrm{JCV}$ and/or BKV activation. At the same time, HpoVs are ubiquitous and wide spread in the

6 general population [zur Hausen, 2008] and the failure to identify any viral sequences in a number

7 of samples (TABLE II) arises several questions. It might be considered that the

8 immunocompromised state of individuals living with HIV should lead to a rather higher rate of

$9 \mathrm{JCV} / \mathrm{BKV}$ presence than the observed one. The possible explanation of these findings probably

10 lies in the studied material. Detection of specific HPoV sequences in peripheral leucocytes was

11 demonstrated in the current study. According to current knowledge, before the development of

12 viremia and further dissemination, HPoV viruses are found mainly in urothelial cells (Doerries,

13 2004). Actually, the results for the presence of HPoV in the group of HIV-infected persons

14 resemble positivity rates documented in healthy blood donors [Kalvatchev et al., 2009].

15 As for the CCR5 co-receptor, it is well established that two types of genetic

16 polymorphisms are observed: in the open reading frame-CCR5del32; and in the gene regulatory

17 region. Here only the genetic polymorphism in the open reading frame but not in the regulatory

18 region - especially the 59029 - G/A, for which its role together with CCR5del32 has been

19 recently confirmed to be associated with disease progression and neurological impairment

20 [Singh et al., 2003], was studied. On the other hand, CCR5 is a co-receptor that facilitates the

21 entry of HIV in CD4+ T cells and the macrophage lineage. Similar to Guerini et al. (2008), no

22 differences in CCR5del32 polymorphism (heterozygocity) between HPoV infected and

23 uninfected persons with HIV infection were found in the present study. The same is valid for the

24 wild type of the CCR5 suggesting the presence of a functioning co-receptor. As individuals with 
1 absent or incomplete expression of one or more chemokine co-receptors have a lower chance to

2 become infected with certain types of HIV and to progress to AIDS [Su et al., 2000], it is possible

3 that the restricted expression of co-receptors might also have a protective role in relation to the

$4 \mathrm{HPoV}$ infection and its associated disease. It could be also theorized that if the HPoV exploit the

5 same co-receptors as those used by HIV, new opportunities for protection and treatment of these

6 opportunistic infections could be provided. Additional research and prospective monitoring of

7 HIV-infected persons with or without progressive multifocal leucoencephalopathy are required.

\section{ACKNOWLEGMENTS}

10 The financial support of Research Medical Council, Medical University, Sofia, Bulgaria

11 and Ministry of Science and Education, Republic of Bulgaria - Research Grant L-1506/05 are 12 highly appreciated.

\section{REFERENCES}

15 Albright AV, Stritzki J, Harouse JM, Lavi E, O'Connor M, Gonzalez-Scarano F. 1996. HIV-1 16 infection of Cultured Human Adult Oligodendrocytes. Virology 217: 211-219.

17 Antinori A, Massari A, Giancola M, Cingolani A, Grisetti S, Murri R, Alba L, Ciancio B, Soldani

18 F, Larussa D, Ippolito G, De Luca A. 2001. Epidemiology and prognosis of AIDS-associated 19 progressive multifocal leukoencephalopathy in the HAART era. J. Neurovirol. 7: 323-328.

20 Borissov K, Markova R, Elenkov I, Kostov K, Savov A, Kremensky I, Argirova R. 2007. Genetic 21 polymorphism of chemokine co-receptors CCR5, CXCR4 and CCR2 in Bulgarians living 22 with HIV. Biotechnol. Biotechnol. Eq. 21: 328-334. 
1 Cartier L, Hartley O, Dubois-Dauphin M, Krause KH. 2005. Chemokine receptors in the central 2 nervous system: role in brain inflammation and neurodegenerative diseases. Brain Res. Brain 3 Res. Rev. 48: 16-42.

4 Chapagain ML, Sumibcay L, Gurjav U, Kaufusi PH, Kast RE, Nerurkar VR. 2008. Serotonin 5 receptor $2 \mathrm{~A}$ blocker (risperidone) has no effect on human polyomavirus JC infection of 6 primary human fetal glial cells. J. Neurovirol. 14: 448-454.

7 Cole CN, Conzen SD. 2001. Polyomaviridae: The viruses and their replication. In: Knipe D and 8 Howley P, editors. Fields Virology, IVth ed., Philadelphia, Lippincott Williams \& Wilkins, $9 \quad$ vol.2, $2141 \mathrm{p}$.

10 Doerries K. 2004. Human Polyomaviruses. In: Zuckerman AJ, Banatvala JE, Pattison JR, 11 Griffiths PD, Schoub BD, editors. Principles and Practice of Clinical Virology. Fifth Ed. 12 Hoboken: John Wiley and Sons Ltd., p. 675-703.

13 Elphick GF, Querbes W, Jordan JA, Gee GV, Eash S, Manley K, Dugan A, Stanifer M, 14 Bhatnagar A, Kroeze WK, Roth BL, Atwood WJ. 2004. The human polyomavirus, JCV, uses 15 serotonin receptors to infect cells. Science 306:1380-1383.

16 Greenlee JE, O'Neill FP. 2002. Polyomaviruses. In: Richman D, R. Whitley, F. Hayden, editors.

17 Clinical Virology. Washington DC: ASM Press, p. 537-555.

18 Guerini FR, Delbue S, Zanzottera M, Agliardi C, Saresella M, Mancuso R, Maserati R, 19 Marchioni E, Gori A, Ferrante P. 2008. Analysis of CCR5, CCR2, SDF1 and RANTES gene 20 polymorphisms in subjects with HIVrelated PML and not determined leukoencephalopathy. 21 Biomedicine and Pharmacotherapy 62: 26-30.

22 Hoffmann C. 2005. Opportunistic Infections (OIs). In: Hoffmann C, Rockstroh J, Kamps B, 23 editors. HIVMedicine. Duesseldorf: Flying publisher, p. 411-415. 
1 Kalvatchev Z, Popov R, Mekushinov K. 2009. Latent $B K$-polyomavirus infection among blood

2 donors. Military Medicine 2: in press.

3 Kaul M, Garden GA, Lipton SA. 2001. Pathways to neuronal injury and apoptosis in HIV$4 \quad$ associated dementia. Nature 410: 988-994.

5 Lu X, Silver J. 2000. Ecotropic murine leukemia virus receptor is physically associated with $6 \quad$ caveolin and membrane rafts. Virology 276: 251-258.

7 MacKenzie J, Wilson KS, Perry J, Gallagher A, Jarrett RF. 2003. Association between simian

8 virus 40 DNA and lymphoma in the United Kingdom. J. Natl. Cancer Inst. 95: 1001-1003.

9 Manes S, Mira E, Gomez-Mouton C, Lacalle RA, Keller P, Labrador JP, Martinez AC. 1999.

10 Membrane raft microdomains mediate front-rear polarity in migrating cells. EMBO J. 18:

$11 \quad 6211-6220$.

12 Millan J, Cerny J, Horejsi V, Alonso MA. 1999. CD4 segregates into specific detergent-resistant

13 T-cell membrane microdomains. Tissue Antigens 53: 33 -40.

14 Nathanson N, Gonzales-Scarano F. 2007. Viral Persistence. In: Nathanson N editor. Viral 15 Pathogenesis and Immunity. Basel: Elsevier, p. 130-145.

16 Nguyen DH, Hildreth JEK. 2000. Evidence for budding of human immunodeficiency virus type 1

17 selectively from glycolipid-enriched membrane lipid rafts. J. Virol. 74: 3264-3272.

18 Ono A, Freed EO. 2001. Plasma membrane rafts play a critical role in HIV-1 assembly and

19 release. Proc. Natl. Acad. Sci. USA 98: 13925-13930.

20 Parton RG, Lindsay M. 1999. Exploitation of major histocompatibility complex class I molecules

21 and caveolae by simian virus 40. Immunol. Rev. 168: 23-31.

22 Pelkmans L, Kartenbeck J, Helenius A. 2001. Caveolar endocytosis of simian virus 40 reveals a

23 new two-step vesicular-transport pathway to the ER. Nat. Cell. Biol. 3: 473-483. 
1 Popik W, Alce TM, Au WC. 2002. Human Immunodeficiency Virus Type 1 Uses Lipid Raft-

2 Colocalized CD4 and Chemokine Receptors for Productive Entry into CD4positive T Cells. J.

$3 \quad$ Virol. 76: $4709-4722$.

4 Sharp CP, Norja P, Anthony I, Bell JE, Simmonds P. 2009. Reactivation and Mutation of Newly

5 Discovered WU, KI, and Merkel Cell Carcinoma Polyomaviruses in Immunosuppressed

$6 \quad$ Individuals. J. Infect. Dis. 199: 398-404.

7 Singer II, Scott S, Kawka DW, Chin J, Daugherty BL, DeMartino JA, DiSalvo J, Gould SL,

8 Lineberger JE, Malkowitz L, Miller MD, Mitnaul L. 2001. CCR5, CXCR4, and CD4 are

9 clustered and closely apposed on microvilli of human macrophages and T cells. J. Virol. 75:

$10 \quad 3779-3790$.

11 Singh KK, Barroga CF, Hughes MD, Chen J, Raskino C, McKinney RE Jr, Spector SA. 2003.

12 Genetic influence of CCR5, CCR2, and SDF1 variants on human immunodeficiency virus 1

13 (HIV-1)-related disease progression and neurological impairment, in children with 14 symptomatic HIV-1 infection. J. Infect. Dis. 188: 1461-1472.

15 Slavov S, Kalvatchev Z, Tsekov I, Simeonov E, Hristova L, Kotsev J, Mladenov D, Tsvetkov M. 16 2008. Novel Light-Upon-Extension (LUX) realtime PCR primer system for rapid detection of 17 Polyomavirus Hominis 1 (BKV) in clinical samples. Biothechnol. Biotechnol. Eq. 22: 759$18 \quad 761$

19 Su B, Guangyan S, Daru L, Junhua S, Fang H, Ranajit C, Ranjan D, Li J. 2000. Distribution of 20 three HIV-1 resistance-conferring polymorphisms (SDF1-3'A, CCR2-64I, and CCR5del32) in 21 global populations. Europ. J. Hum. Genetics 8: 975-979.

22 Vallbracht A, Löhler J, Gossmann J, Glück T, Petersen D, Gerth HJ, Gencic M, Dörries K. 1993.

23 Disseminated BK type polyomavirus infection in an AIDS patient associated with central 24 nervous system disease. Am. J. Pathol. 143: 29-39. 
1

2

3

4

5

6

7

8

9

10

11

12

13

14

15

16

17

18

19

20

21

22

23

24

25

26

27

28

29

30

31

32

33

34

35

36

37

38

39

40

41

42

43

44

45

46

47

48

49

50

51

52

53

54

55

56

57

58

59

60
1 Zur Hausen H. 2008. Novel human polyomaviruses - Re-emergence of a well known virus

2 family as possible human carcinogens. Int. J. Cancer 123: 247-250. 